\title{
Attempts to Minimizing Incisal Pin Opening During Processing of Complete Dentures
}

\author{
Rizgar Mohammed Ameen Hasan ${ }^{(1)}$
}

Background and objectives: Dimensional changes associated with the processing of complete dentures is one of most important problems of acrylic resin denture base materials, these changes lead to series of problems clinically. The aim of this study was to try new attempts to minimizing the post processing dimensional changes.

Methods: Forty-two identical maxillary waxed dentures prepared, each of them mounted on an articulator. The initial dimension was measured between the upper and lower members of the articulator before processing, after processing and remounting of the dentures the measurements recorded after deflasking and decasting, comparing these measurements with the initial measurement determined the incisal pin opening (IPO). Two new attempts for decreasing IPO have been tested by modifying the conventional waxed dentures, in the first attempt five wax sprues added to the flanges while in the second attempt four wax sprues added to the palatal surfaces of the waxed dentures. The waxed dentures processed in two types of heat curing acrylic resins.

Results: The results showed that both new attempts caused decreasing in the dimensional changes and IPO at both times after deflasking and decasting.

Conclusion: It had been concluded that the addition of four waxed sprues will significantly decrease the IPO.

Keywords: Incisal pin opening; vertical dimension of occlusion; dimensional changes; Attempts

(1) B.D.S., M. Sc., Ph.D., Lecturer at the College of Dentistry- Hawler Medical University.

\section{Introduction}

The denture bases made of acrylic resin are preferred due to their easy fabrication, easy repair, adjustment and relining. In addition to these benefits, heat curing acrylic resin denture bases are very economic, provide color stability, highly smooth surface, and relatively easily cleaned. ${ }^{1-4}$ For the construction of denture base the most commonly used material is acrylic resin, but it is distorted during acrylic processing and throughout clinical use and it changes dimensionally. ${ }^{5}$ These changes of acrylic resin affects the denture stability, cause inappropriate adaptation of the denture base to the oral tissue and changes of the positions of the artificial teeth. ${ }^{6}$

Complete denture processing may cause changes, these common changes may cause alterations of occlusal vertical dimension (OVD). ${ }^{7,8}$ The phonetics, adaptation and retention of the prostheses, and the esthetics can be compromised by these changes. ${ }^{9}$ For the elderly, these changes may ultimately result in longer periods of adaptation and patient dissatisfaction. ${ }^{9,10}$ During denture construction, distortions cannot be avoided. The dimensional changes cause alterations in the OVD, ${ }^{11,12}$ which 
may lead to irregular distribution of dental stresses on the residual alveolar ridge, traumatic occlusion, masticatory inefficiency, and difficulty in adaptation. ${ }^{13,14}$ Under clinical conditions, modification of the planned vertical occlusion dimension may be caused by these dimensional changes, which causes bone loss and traumas in mucosa. ${ }^{15}$

Injection molding techniques and microwave polymerization are reported to improve clinical fit and reduce dimensional changes. Still many laboratories use compression molding technique and these new techniques did not gain popularity. ${ }^{16}$

Acrylic resin complete dentures undergo thermal expansion during heating, contraction during cooling, and shrinkage during polymerization. ${ }^{17}$ The inherent characteristics of this material produce internal stresses that is released during deflasking stage, generating dimensional changes and denture base distortion. $^{18}$

Studies focusing on acrylic resin properties and laboratory steps for complete denture processing are common in the dental literature. ${ }^{14,19,20}$ Migration of artificial teeth in the mold commonly occurs in compression molding technique. ${ }^{21-23}$ The resultant shift affects the planned occlusion adversely, and it is manifested by the loss of contact between the incisal pin and the incisal table of the articulator. ${ }^{24-26}$ A clinically significant incisal pin opening (IPO) may occur after complete dentures processing by compression molding technique. $^{27}$ IPO is used by the examining members of the American Board of Prosthodontics as a criterion in evaluation of the quality of the procedure. ${ }^{28}$

The objective of the present study was to evaluate two new procedures as attempts to reduce IPO. Many previous studies tried to decrease IPO by improving the techniques and the materials used during processing of denture bases. However, to the author's knowledge; no previous studies tried to add wax sprues to the waxed dentures to aid in improving the dimensional stability of the complete dentures.

\section{Materials and methods}

A total of 42 identical maxillary edentulous casts, produced from pouring a mixture of type III dental stone (BlauStone, Lot No. 22070306, Efes Dental, Turkey) prepared according to the manufactures instructions into a standard rubber mold. A triangle shaped reference with the depth of $2 \mathrm{~mm}$ were prepared on the base of each cast, and for each cast a baseplate of double thickness wax (QWax, Lot No. 4052486, Efes Dental, Turkey) was constructed.

Forty-two maxillary sets of acrylic resin teeth (Major Dent, Major Prodotti Dentari S.P.A, Italy) of the same mold, size and from the same manufacturer were used. The teeth were arranged for one of the casts in conventional manner, all the incisal edges and cusps of the teeth were in contact with mounting platform of the articulator. A silicone mold made around the facial and palatal surfaces of the arranged teeth, which was used as a key for producing similar arrangement of the artificial teeth on all the casts. Waxing and festooning performed for all the maxillary waxed dentures. Each waxed denture was mounted on an articulator (ASA DENTAL- Anatomical Articulator 5010, Italy) using dental plaster, the midline faced the vnotch present in the anterior portion of the mounting platform and posterior teeth placed parallel to the posterior flange of the platform, care was taken that there was contact of all the incisal edges and cusps with the mounting platform. After the mounting plaster was set any space occurred between incisal guide pin and incisal guide table due to setting expansion was closed by adjusting and lowering the incisal pin to be in contact with the incisal guide table (Figure 1).

The waxed dentures were divided into three equal main groups, the first group was the control group, processed in conventional compression molding technique without any 
modifications, while the second and third groups were modified as attempts to decreasing the dimensional changes of processed dentures.

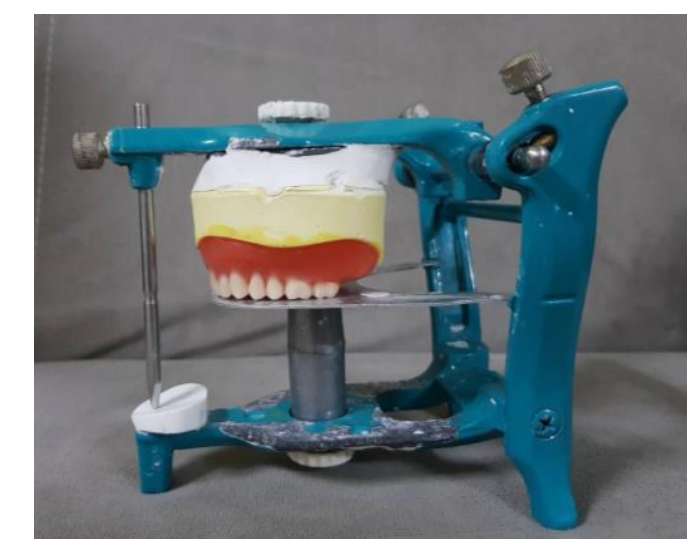

Figure1: Maxillary waxed denture mounted on the articulator.

First Attempt. The second group was modified by adding five wax sprues, the diameter of $4 \mathrm{~mm}$ and length of $10 \mathrm{~mm}$, of blue sprue wax ( BlauWax, BlauDent ${ }^{\circledR}$, Efes Dental, Turkey) on the facial surface on the flanges of the waxed dentures. The first sprue was placed between the two central incisors, the second and third were placed between the canine and the first premolar on both the right and the left sides, while the fourth and fifth sprues were place on both the right and the left sides opposite to the first molars. the sprues were joined by a heated instrument, at $45^{\circ}$ to the flanges (Figure 2).

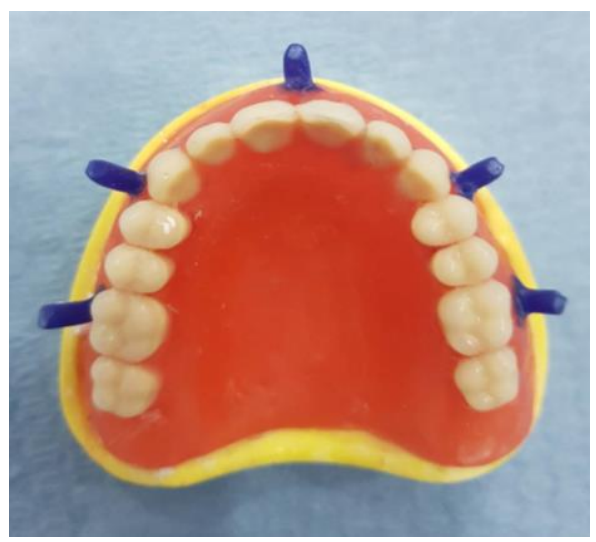

Figure 2: Five wax sprues added to the flanges of the waxed denture.
Second Attempt. The third group was also modified by adding four wax sprues. In this attempt the wax sprues were added on the palatal surfaces of the waxed dentures with previously mentioned dimensions and type. The sprues were placed as follow: the first sprue was placed in the middle of a line joining both the right and the left canines, the second was placed in the middle of a line joining both the right and the left second premolars, while the third and fourth sprues were placed slightly posterior to the palatal surfaces of the right and the left second molars, all the sprues were joined by using a hot instrument perpendicularly to the palatal surface of the waxed dentures (Figure 3).

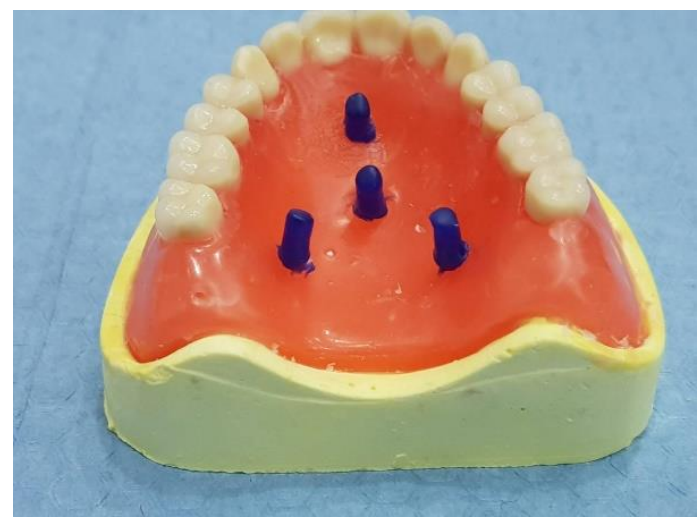

Figure3: Four wax sprues added to the palatal portion of the waxed denture.

Groups. The 3 main groups were subdivided into two groups the 1st group was processed using D Line heat curing acrylic (Made in EU for D line OU, Medicinos Linjia, Lithuania, Lot No. of the powder:170109, Lot No. of the liquid: 161129), while for the other group SR Triplex heat curing acrylic resin (Ivoclar Vivadent AG, Liechtenstein. Lot No. of the powder: W36366, Lot No. of the liquid: W38327) was used.

All the waxed denture were divided into six groups: $1^{\text {st }}$ group (DC) control and D Line acrylic, $2^{\text {nd }}$ group (DB) modified with buccal sprues and D Line acrylic, $3^{\text {rd }}$ group (DP) modified with palatal sprues and D Line acrylic, $4^{\text {th }}$ group (TC) control and SR Triplex 
acrylic, $5^{\text {th }}$ group (TB) modified with buccal sprues and SR Triplex acrylic, $6^{\text {th }}$ group (TP) modified with palatal sprues and SR Triplex acrylic.

Processing of the waxed dentures. All waxed dentures were processed following the conventional compression molding technique, the waxed dentures were invested by two layers of plaster and a third layer (capping) of stone capping. The heat curing acrylic resin packed using hydraulic press with two trial closures of the flasks and processed following the manufacturers' instructions using electrical Hanau hot water curing unit.

Measurement of dimensional changes and IPO. Before processing of the waxed dentures, after setting of mounting plaster and adjusting the incisal pin to get a full contact between incisal pin and guide, an initial measurement was recorded for each waxed denture with a digital vernier (Mitutoy, model number: Us Ms00 13, model: 500 series, Japan) accurate to $0.01 \mathrm{~mm}$. The distance measured between the top of upper member of the articulator just behind the top of incisal pin and bottom of lower member of the articulator just behind the incisal guide plate, for standardization the two positions were determined with a permanent marker (Figure 4). After processing, and while the acrylic resin dentures were still on their casts just after deflasking; the processed denture with its cast were remounted on the articulator with the aid of the reference triangles on the base of the casts. A second measurement was recorded between the two mentioned positions. Another third measurement was recorded for the distance between the same positions after removing the dentures from their casts (decasting).

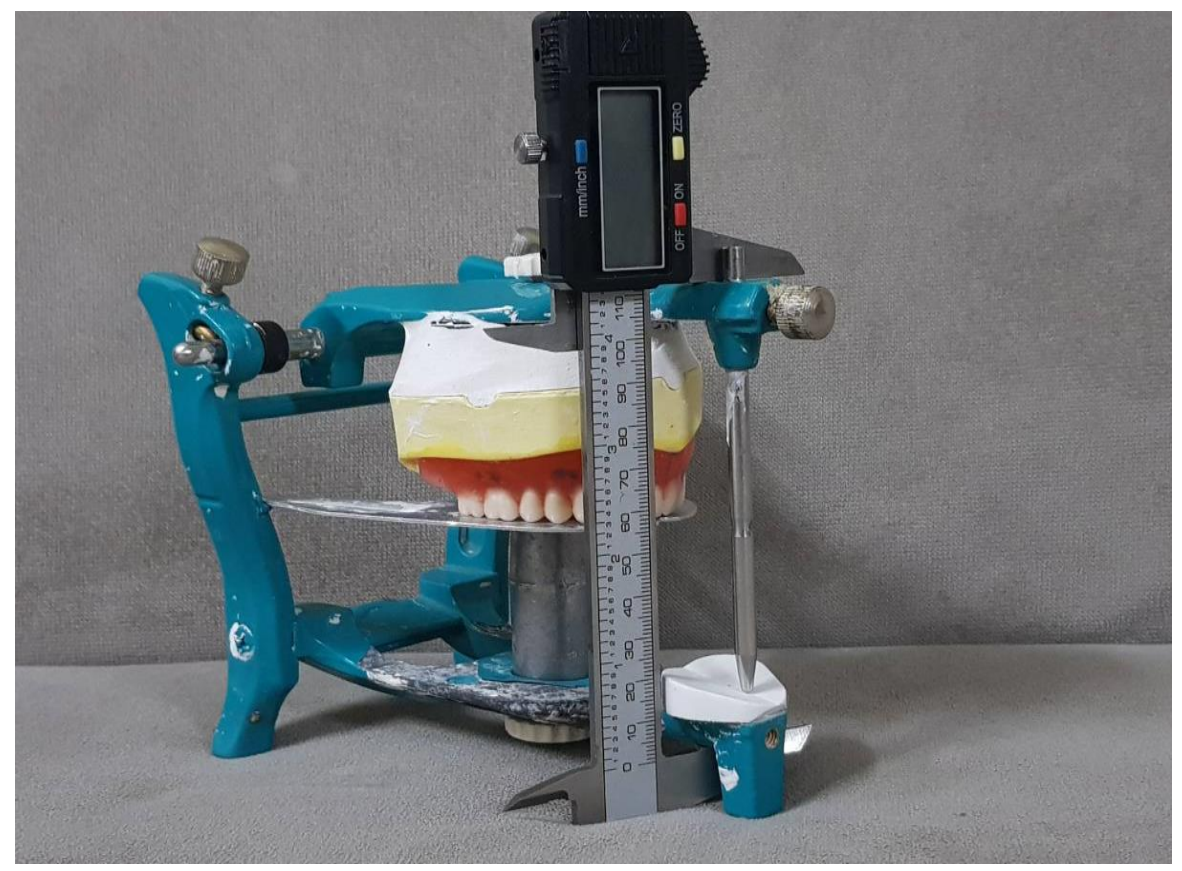

Figure 4: Measurement the vertical dimension before processing of the complete denture.

The dimensional changes were calculated by recording the results of subtracting the measurement after deflasking and initial measurement, also the results of subtracting the measurement after decasting and initial measurement were recorded alone.
Data Analysis. The statistical package for Microsoft Windows ${ }^{\circledR}$ (SPSS version 23) was used to analyze the data, student t-test was carried out to determine the significance of difference between the specimens of the processed dentures of the two groups (non- 
modified and modified specimens). A $P$-value $\leq 0.05$ was considered statistically significant.

\section{Results}

The mean values and standard deviations of IPO occurred for all groups after deflasking and decasting are shown in the Table1. The results revealed that IPO occurred in all groups in both times following deflasking and decasting. The mean of VDO changes $(\mathrm{mm})$ in different groups after deflasking were: group $1(0.872 \pm$ $0.057)$, group $2(0.295 \pm 0.0282)$, group 3
$(0.301 \pm 0.063)$, group $4(0.384 \pm 0.022)$, group $5(0.227 \pm 0.042)$ and group $6(0.382 \pm 0.038)$. While The Mean of IPO in different groups after decasting were: group 1 (1.1729 \pm $0.06921)$, group $2(0.5929 \pm 0.05851)$, group 3 $(0.604 \pm 0.072)$, group $4(0.872 \pm 0.050)$ group $5(0.447 \pm 0.026)$ and group $6(0.827 \pm 0.065)$. The highest mean value of increased IPO appeared in Group1 after decasting, while the lowest mean of IPO was seen in Group 5 after deflasking.

Table1: The mean values and standard deviation of IPO occurred at all groups after deflasking and decasting.

\begin{tabular}{|c|c|c|c|c|}
\hline $\begin{array}{c}\text { Groups and time of } \\
\text { measurement }\end{array}$ & $\mathbf{N}$ & $\begin{array}{c}\text { Mean } \\
(\mathbf{m m})\end{array}$ & Std. Deviation & $\begin{array}{c}\text { Std. Error } \\
\text { Mean }\end{array}$ \\
\hline DC_Deflasking & 7 & 0.8729 & 0.05794 & 0.02190 \\
\hline DB_Deflasking & 7 & 0.2957 & 0.02820 & 0.01066 \\
\hline DP_Deflasking & 7 & 0.3014 & 0.06362 & 0.02405 \\
\hline TC_Deflasking & 7 & 0.3843 & 0.02225 & 0.00841 \\
\hline TB_Deflasking & 7 & 0.2271 & 0.04231 & 0.01599 \\
\hline TP_Deflasking & 7 & 0.3829 & 0.03829 & 0.00522 \\
\hline DC_Decasting & 7 & 1.1729 & 0.06921 & 0.02616 \\
\hline DB_Decasting & 7 & 0.5929 & 0.05851 & 0.02212 \\
\hline DP_Decasting & 7 & 0.6043 & 0.07208 & 0.02724 \\
\hline TC_Decasting & 7 & 0.8729 & 0.05090 & 0.01924 \\
\hline TB_Decasting & 7 & 0.4471 & 0.02690 & 0.01017 \\
\hline TP_Decasting & 7 & 0.8271 & 0.06550 & 0.02476 \\
\hline
\end{tabular}

From the results of this study that are shown in Table 1, it had been noted that both the new attempts showed reduction in the dimensional changes of IPO at both times after deflasking and decasting and for both types of the heat curing acrylic resins when compared to the control groups. The results were analyzed by student's t-test, paired at 95\% level of confidence $(P=0.05)$. The results of statistical analysis are shown in Table 2. All the differences between the groups were significant for changes of IPO, except the differences between TC and TP at deflasking, and the differences between $\mathrm{TC}$ and $\mathrm{TP}$ at decasting, where the differences were nonsignificant. 
Table 2: Student's t-test of IPO differences comparing the groups after polymerization.

\begin{tabular}{|c|c|c|c|c|c|c|c|}
\hline \multicolumn{2}{|c|}{ Paired Samples Statistics } & \multirow{2}{*}{$\begin{array}{c}\mathbf{N} \\
7\end{array}$} & \multirow{2}{*}{$\begin{array}{c}\begin{array}{c}\text { Mean } \\
(\mathrm{mm})\end{array} \\
0.8729\end{array}$} & \multirow{3}{*}{$\begin{array}{c}\text { Sig. } \\
0.998\end{array}$} & \multirow{3}{*}{$\begin{array}{c}\mathrm{T} \\
23.683\end{array}$} & \multirow{3}{*}{$\begin{array}{l}\text { Df } \\
6\end{array}$} & \multirow{3}{*}{$\begin{array}{l}\text { Sig. (2-tailed) } \\
\quad<0.001^{*}\end{array}$} \\
\hline \multirow{2}{*}{ Pair 1} & DC_Deflasking & & & & & & \\
\hline & DB_Deflasking & 7 & 0.2957 & & & & \\
\hline \multirow{2}{*}{ Pair 2} & DC_Deflasking & 7 & 0.8729 & \multirow{2}{*}{0.175} & \multirow{2}{*}{26.948} & \multirow{2}{*}{6} & \multirow{2}{*}{$<0.001^{*}$} \\
\hline & DP_Deflasking & 7 & 0.3014 & & & & \\
\hline \multirow{2}{*}{ Pair 3} & TC_Deflasking & 7 & 0.3843 & \multirow{2}{*}{0.700} & \multirow{2}{*}{8.117} & \multirow{2}{*}{6} & \multirow{2}{*}{$<0.001^{*}$} \\
\hline & TB_Deflasking & 7 & 0.2271 & & & & \\
\hline \multirow{2}{*}{ Pair 4} & TC_Deflasking & 7 & 0.3843 & \multirow{2}{*}{0.275} & \multirow{2}{*}{0.121} & \multirow{2}{*}{6} & \multirow{2}{*}{$0.908^{* *}$} \\
\hline & TP_Deflasking & 7 & 0.3829 & & & & \\
\hline \multirow{2}{*}{ Pair 5} & DC_Decasting & 7 & 1.1729 & \multirow{2}{*}{0.034} & \multirow{2}{*}{12.685} & \multirow{2}{*}{6} & \multirow{2}{*}{$<0.001^{*}$} \\
\hline & DB_Decasting & 7 & 0.5929 & & & & \\
\hline \multirow{2}{*}{ Pair 6} & DC_Decasting & 7 & 1.1729 & \multirow{2}{*}{0.892} & \multirow{2}{*}{15.559} & \multirow{2}{*}{6} & \multirow{2}{*}{$<0.001^{*}$} \\
\hline & DP_Decasting & 7 & 0.6043 & & & & \\
\hline \multirow{2}{*}{ Pair 7} & TC_Decasting & 7 & 0.8729 & \multirow{2}{*}{0.260} & \multirow{2}{*}{25.429} & \multirow{2}{*}{6} & $<0.001 *$ \\
\hline & TB_Decasting & 7 & 0.4471 & & & & \\
\hline & TC_Decasting & 7 & 0.8729 & & & & \\
\hline anto & TP_Decasting & 7 & 0.8271 & $0.5<0$ & טכJ.1 & & $0.10<$ \\
\hline
\end{tabular}

* Significant, ** Non-significant

\section{Discussion}

Although many improvements have been applied to the heat curing acrylic resin denture base materials and new techniques have been used for processing the denture bases, dimensional changes and IPO remained as disadvantages of these materials. In this study the IPO occurred in all the processed dentures for the two brands of acrylic resins and in both situations deflasking and decasting (Table 1). The mean of the IPO occurred in the control groups was nearly similar to previous studies. ${ }^{10}$, 26, 29
In the present study, two new attempts have been used to overcome the problem and to minimize the vertical dimensional changes and the amount of the IPO, and to produce less subsequent problems. Both attempts were performed by the addition of wax sprues to the waxed dentures. The wax sprue is easily available, can be adapted easily and sealed to the denture bases, do not affect the cost of processing procedures and no need for extra equipments. The presence of the wax sprues in both attempts significantly minimized the dimensional changes and the amount of the IPO 
associated with denture processing at both decasting and deflasking stages and for the two brands of heat curing acrylic resins. Since the attempts were new and there was no previous similar researches; it was not possible to compare the results with other studies.

Decreased number of the occlusal contacts and the increased VDO may be related to compression during molding, to the heating intensity and duration, or may be related to the non-uniform thickness in the flanges, ${ }^{30}$ since the inherent characteristics of heat curing acrylic resin produce internal stresses that are released during the deflasking stage, which result in dimensional changes and denture base distortion. ${ }^{18}$ It is thought that minimizing the IPO was due to the release of the strain through the free ends of the sprues where the packing pressure of the acrylic resin produce strain inside the denture base and the acrylic injected within the holes produced by the wax elimination of the sprues. After deflasking and decasting, the strain produced within the processed denture base is easily released through the free end acrylic sprues that minimize the distortion with the base and cause less migration of the artificial teeth and subsequently less IPO. Another cause of the less recorded IPO may be due the presence of excess acrylic resin that had remained after the second trial closure and removal of the acrylic resin flash that had been confined within the flask, may be the excess of the acrylic resin have been injected into the holes produced inside the second layer of plaster of flasking by the presence of the sprue wax.

\section{Conclusion}

Within the limitation of this study, it had been observed that both the two new attempts by adding wax sprues to the flanges and the palatal surface of the waxed dentures, significantly minimized the amount of IPO and produced less vertical dimensional changes of the processed complete dentures after deflasking and decasting.

\section{Conflicts of interest}

The author reported no conflicts of interest.

\section{References}

1- Lerner $H$, Pfeiffer KR. Minimum vertical occlusal changes in cured acrylic resin dentures. J Prosthet Dent 1964; 14: 294-7.

2- Zakhari KN. Relationship of investing medium to occlusal changes and vertical opening during construction. J. Prosthet Dent 1976; 36: 501-8.

3- Dukes BS, Fields HJr., Morris JC, Jewell A. A comparative study of changes in vertical dimensions of occlusion using different investment mediums. J Prosthet Dent 1983; 49: 568-71.

4- Finer $Y$, Diwan R. Prosthodontic treatment for edentulous patients: Complete dentures and implant-supported prosthesis. In: Zarb G, Hobkirk JA, Eckert S, Jacob RF, editors. Materials used in management of edentulous patients. 13 ed. St. Louis, Missourri: Mosby ElServier, 2013. p121-60.

5- Negreiros WA, Consani RL, Mesquita MF, Sinhoretiv $M A$, and Faria IR. Effect of flask closure method and post-pressing time on the displacement of maxillary denture teeth. The Open Dentistry Journal 2009; 3:1, 21-5.

6- Lee CJ, Bok SB, Bae JY, Lee HH. Comparative adaptation accuracy of acrylic denture bases evaluated by two different methods. Dental Materials Journal 2010; 29; 4, 411-7.

doi.org: 10.4012/dmj.2009-105

7- Rizzatti-Barbosa CM, Ribeiro-Dasilva MC. Influence of double flask investing and microwave heating on the superficial porosity, surface roughness, and knoop hardness of acrylic resin. J Prosthodont 2009; 18:503-6.

8- Hegde V, Patil N. Comparative evaluation of the effect of palatal vault configuration on dimensional changes in complete denture during processing as well as after water immersion. Indian J Dent Res 2004 ;15: 62-5.

9- Basker RM, Davenport JC, Thomason JM. Prosthetic treatment of the edentulous patient. 5 ed. Nova Jersey: John Wiley \& Sons 2011. p288.

10-Shukor SS, Juszczyk AS, Clark RK, Radford DR. The effect of cyclic drying on dimensional changes of acrylic resin maxillary complete dentures. J Oral Rehabil 2006; 33:654-9.

11- Slaviero TV, Simon GH, Tagliari I, Busato PM, Sinhoreti MA, Camilotti V, Mendonça MJ. Effect of polymerization techniques on vertical dimension and tooth position in complete dentures. Acta Odontol Latinoam 2011; 24:211-7. 
12-Teraoka F, Takahashi J. Controlled polymerization system for fabricating precise dentures. J Prosthet Dent 2000; 83:514-20.

13-Ghani F, Kikuchi M, Lynch CD, Watanabe M. Effect of some curing methods on acrylic maxillary denture base fit. Eur J Prosthodont Restor Dent 2010; 18:1328.

14-Meloto CB, Silva-Concílio LR, Machado C, Ribeiro MC, Joia FA, Rizzatti-Barbosa M. Water sorption of heatpolymerized acrylic resins processed in mono and bimaxillary flasks. Braz Dent J 2006; 17:122-5.

15-McCartney JW. Flange adaptation discrepancy, palatal base distortion, and induced malocclusion caused by processing acrylic resin maxillary complete dentures. J Prosthet Dent 1984; 52:4; 54553.

16- Keenan PL, Radford DR, Clark RK. Dimensional change in complete dentures fabricated by injection molding and microwave processing. J Prosthet Dent 2003; 89: 37-44.

17- Negreiros WA, Consani RLX, Verde M A R L., da Silva AM, Pinto LP. The role of polymerization cycle and post-pressing time on tooth movement in complete dentures. Braz Oral Res 2009; 23: 467-72.

18-Botega DM, Machado TS, Mello JAN, RodriguesGarcia RCM, Cury AADB. Polymerization time for a microwave cured acrylic resin with multiple flasks. Braz Oral Res 2004; 18(1):23-8.

19-John J, Gangadhar SA, Shah I. Flexural strength of heat polymerized polymethyl methacrylate denture resin reinforced with glass, aramid, or nylon fibers. J Prosthet Dent 2001; 86(4):424-7.

20-Barbosa DB, Compagnoni MA, Leles CR. Changes in occlusal vertical dimension in microwave processing of complete dentures. Braz Dent J 2002; 13(3):197200.

21-Vikram J, Choudhary A, Karla H, Vikram A. Investigation into the role of various factors during flasking and packing of heat cure acrylic resin, resulting in occlusal discrepancies in processed complete dentures. Int J Prosthet Dent 2013; 4:4855.

22-Consani RLX, Mesquita MF,Consani S, Sorbinho LC, Souso-Neto MD. Effect of water storage on tooth displacement in maxillary complete dentures. Braz Dent J 2006: 17(1):53-7. doi.org/10.1590/S0103-64402006000100012

23-Babu S, Manjunath S, Vajawat M. Effect of palatal form on movement of teeth during processing of complete denture prosthesis: An in-vitro study. Contemp Clin Dent 2016; 7(1):36-40. doi:10.4103/0976-237X.177101.

24-Nelson MW, Kotwal KR, Sevedge SR. Changes in vertical dimension of occlusion in conventional and microwave processing of complete dentures. J Prosthet Dent 1991; 65: 306-8.

25-Strohaver RA. Comparison of changes in vertical dimension between compression and injection molded complete dentures. J Prosthet Dent 1989; 62:716-8.

26-Hasan RMA. The effect of some processing factors on dimensional changes of rapid heat curing maxillary complete dentures. MSc Thesis, 2002, University of Salahaddin - Erbil.

27-Nogueira SS1, Ogle RE, Davis EL. Comparison of accuracy between compression and injectionmolded complete dentures. 1999 ;82(3):291-300.

28-Kotwal KR, Montoya ML, Colvin C. Minimizing incisal pin opening during complete denture processing. J Prosthet Dent 1988; 60:642-3.

29-Salloum AM. Influence of high expansion dental stone used as investing medium on the changes in occlusal vertical dimension of complete dentures. The Saudi Dental Journal 2013; 25:135-40.

doi.org/10.1016/j.sdentj.2013.10.002

30-Atashrazm P, Alavijeh LZ, Afshar MSS. Influence of the fast-processing technique on the number of the occlusal contacts and occlusal vertical dimension of complete dentures. J Contemp Dent Pract 2011; 12(2):84-90. 